\title{
Author Correction: Genomic analysis finds no evidence of canonical eukaryotic DNA processing complexes in a free-living protist
}

Dayana E. Salas-Leiva (D), Eelco C. Tromer (1), Bruce A. Curtis (D), Jon Jerlström-Hultqvist (1D, Martin Kolisko (D), Zhenzhen Yi(D, Joan S. Salas-Leiva (D), Lucie Gallot-Lavallée (D), Shelby K. Williams (D), Geert J. P. L. Kops (D), John M. Archibald (D), Alastair G. B. Simpson (1) \& Andrew J. Roger (1)

Correction to: Nature Communications https://doi.org/10.1038/s41467-021-26077-2; published online 14 October 2021.

The original version of this Article contained an error in Fig. 1 panel b, which presented a left-handed helix instead of a right-handed helix conformation. Furthermore the labels for the $5^{\prime}$ and $3^{\prime}$ DNA ends and arrows to indicate the progression of DNA synthesis were missing. 
The correct version of Fig. 1 is :

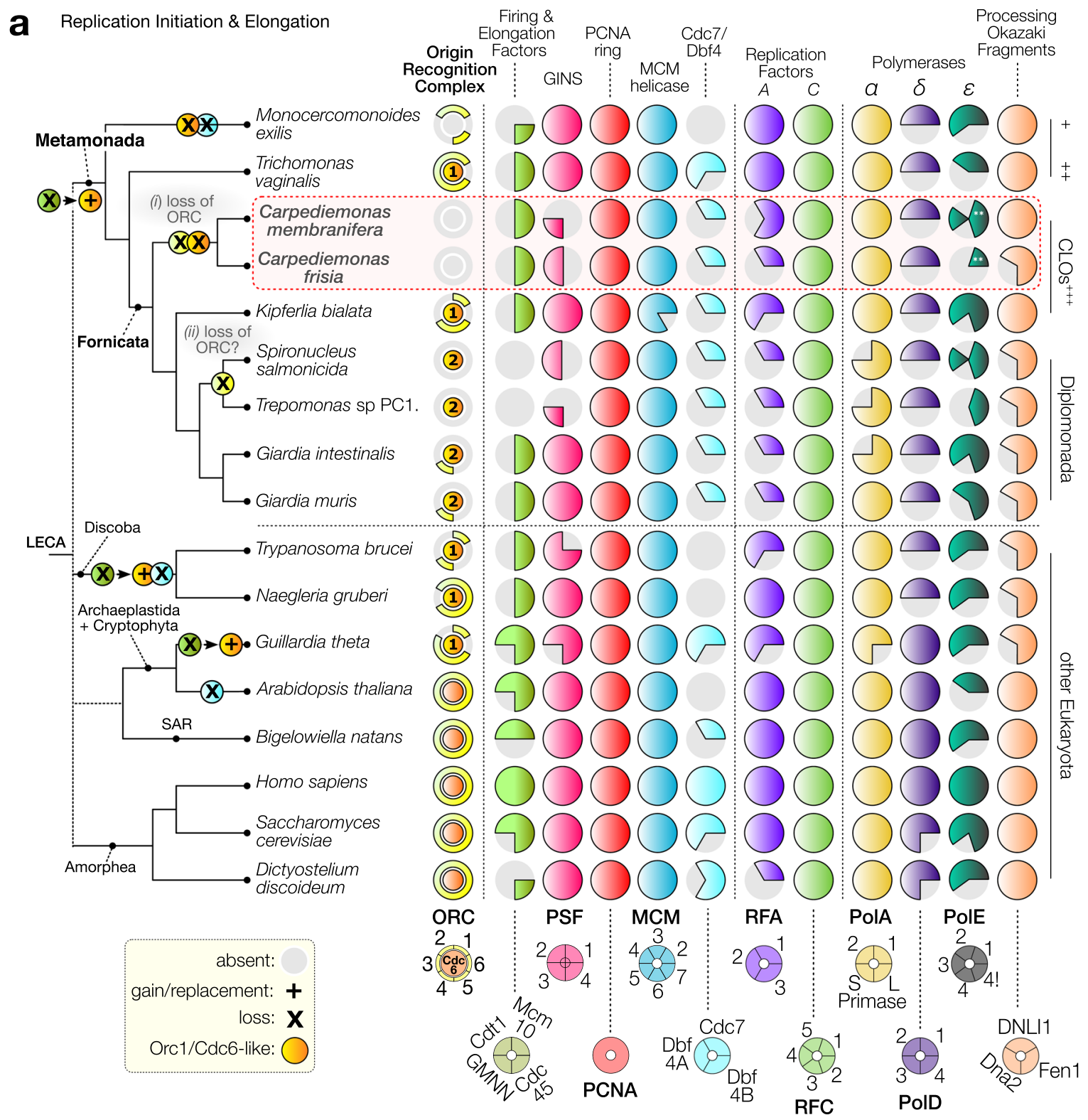

b Carpediemonas membranifera

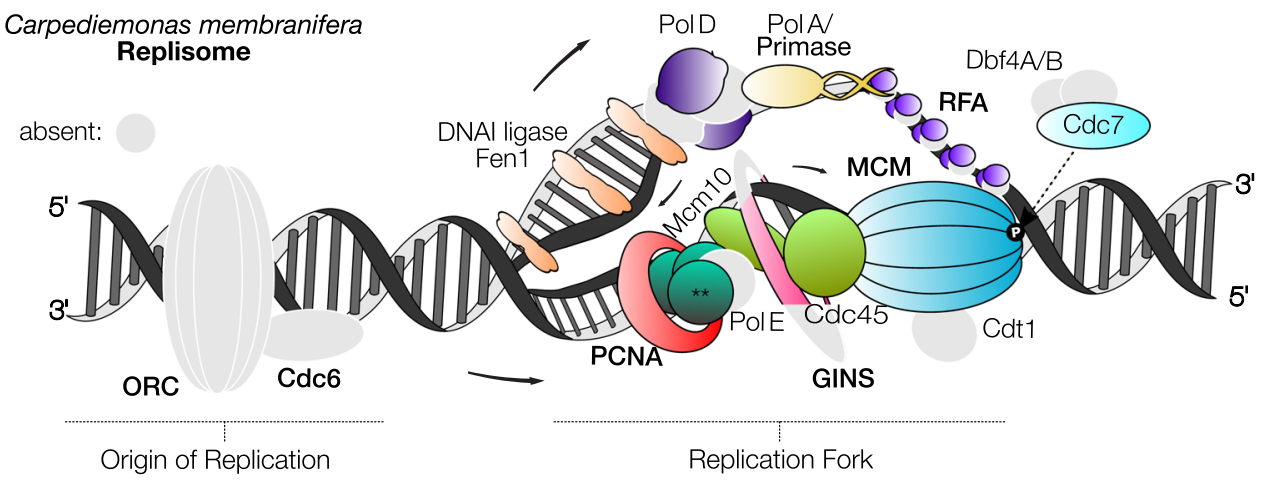


which replaces the previous incorrect version:

a Replication Initiation \& Elongation
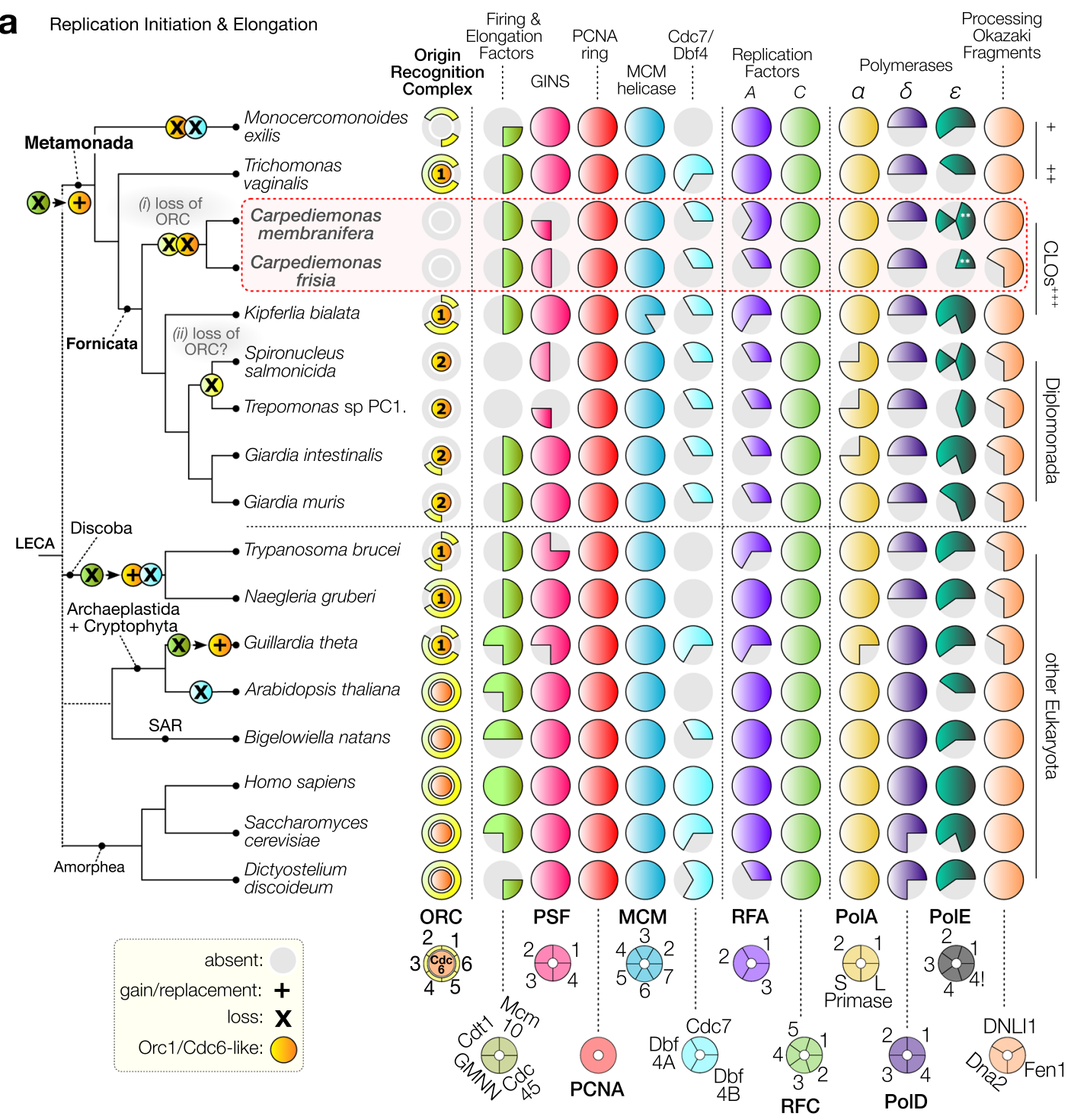

b Carpediemonas membranifera Replisome

absent:
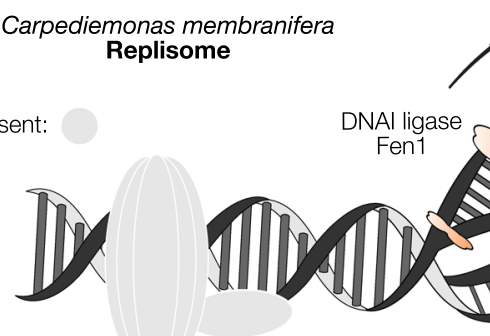

PolD PolA

Primase

Dbf4A/B

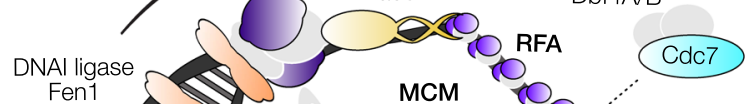

$$
\begin{gathered}
\text { ORC Cdc6 } \\
\text { Origin of Replication }
\end{gathered}
$$

Replication Fork 
The original version of this Article also contained an error in Fig. $4 \mathrm{~b}$ and $\mathrm{c}$, in which the strands of the Holliday junction were switched and Mre11-Rad50 was implicated as a 5'-3' exonuclease.

The correct version of Fig. 4 is :

$?$

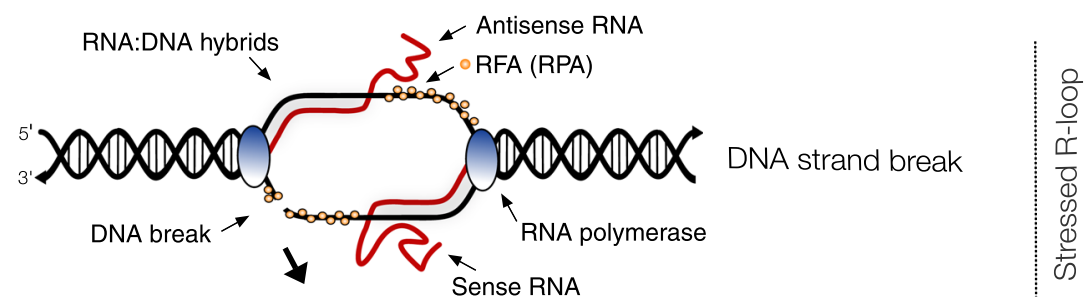

Single to double strand break processing

b

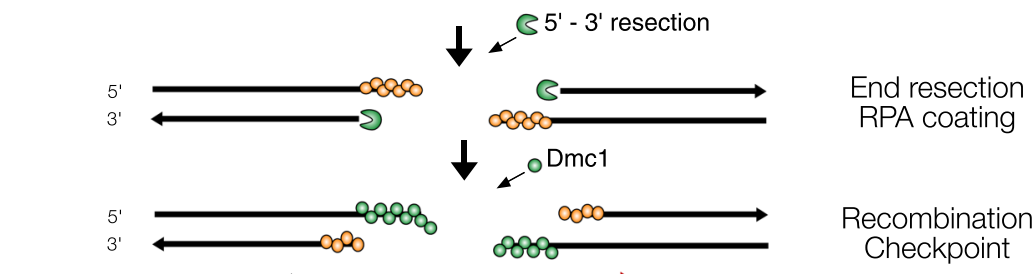

dsRNA or cDNA ? ${ }^{5^{\prime}}$
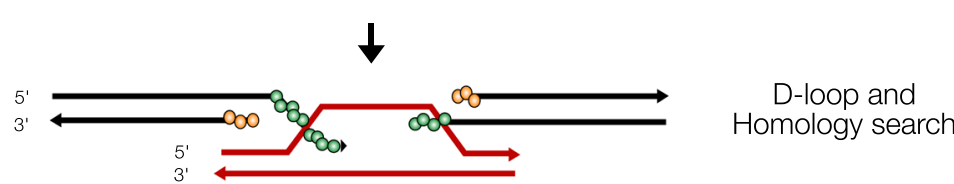

D-loop and

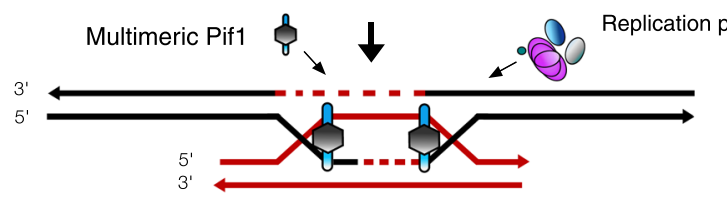

proteins

Holiday Junction

$(\mathrm{HJ})$

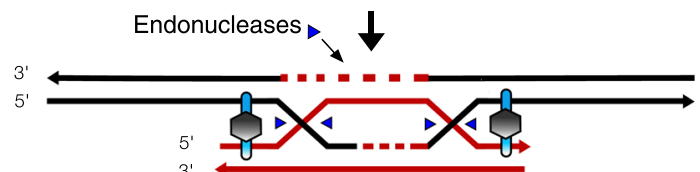

HJ resolution by endonucleases

c

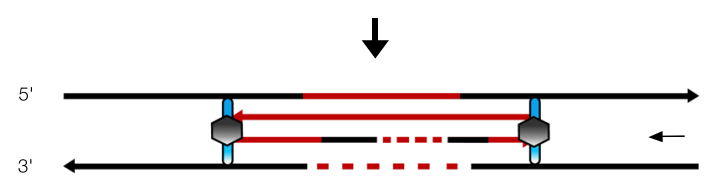

DNA:RNA template resembling

replication intermediates
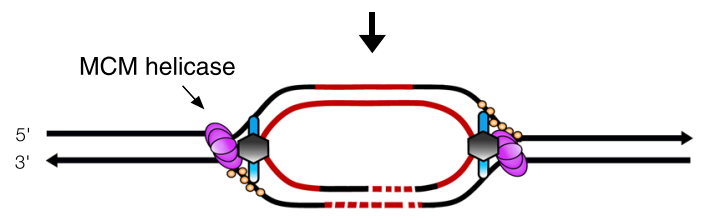

Replication fork
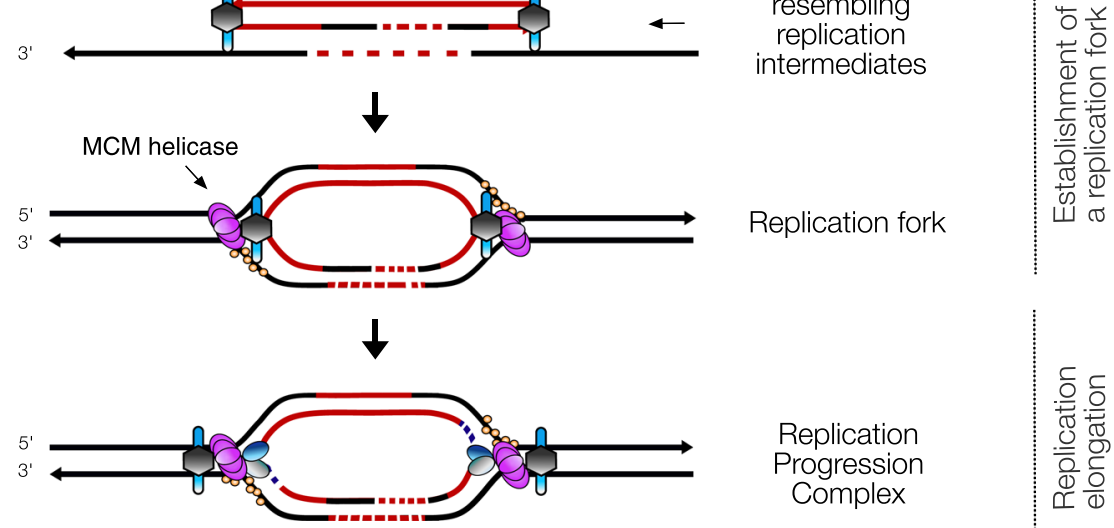

Replication

Progression

Complex

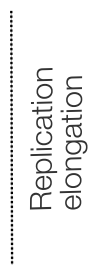


which replaces the previous incorrect version:
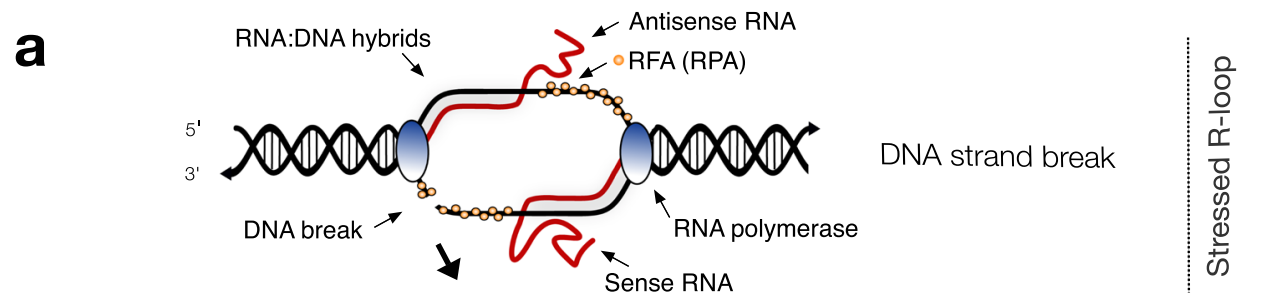

Single to double strand break processing

b
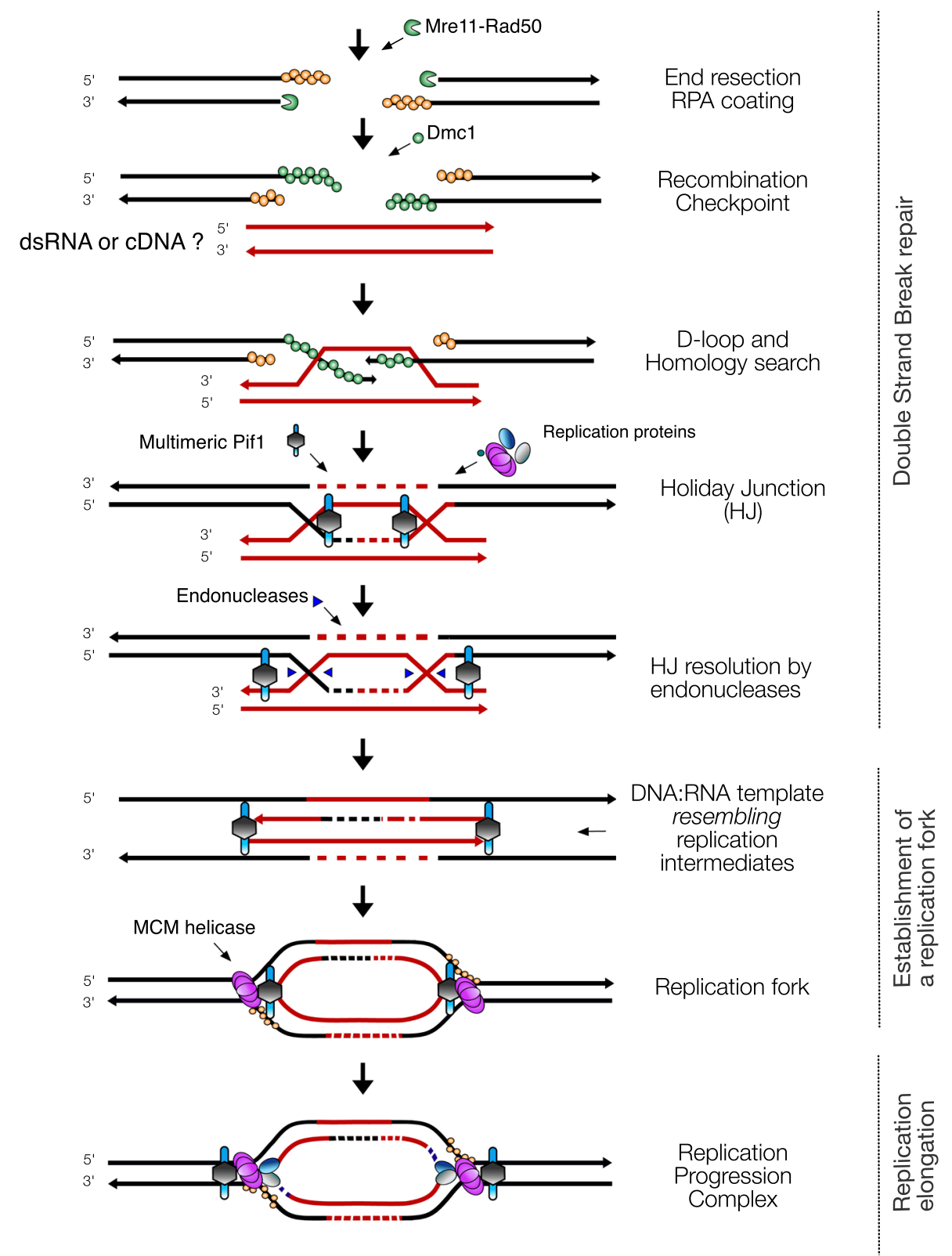

The legend for Fig. 4 incorrectly read ' b Once the damage is processed into a DSB, end resection by Mre11/Rad50 creates a 3' overhang and the strands are coated with replication protein A (RPA), while resected ends are coated with the recombinase Dmc1.' The correct version states ' $\mathbf{b}$ Once the damage is processed into a DSB, end resection creates an overhang, and the strands are coated with replication protein A (RPA), and the recombinase Dmcl.'

The legend also incorrectly stated 'Dark blue fragments on $3^{\prime}$ ends of the bottom figure represent Okazaki fragments.'. In the corrected version, ' 3 " has been removed.

This has been corrected in both the PDF and HTML versions of the Article. 
Published online: 16 December 2021

(c) Open Access This article is licensed under a Creative Commons Attribution 4.0 International License, which permits use, sharing, adaptation, distribution and reproduction in any medium or format, as long as you give appropriate credit to the original author(s) and the source, provide a link to the Creative Commons license, and indicate if changes were made. The images or other third party material in this article are included in the article's Creative Commons license, unless indicated otherwise in a credit line to the material. If material is not included in the article's Creative Commons license and your intended use is not permitted by statutory regulation or exceeds the permitted use, you will need to obtain permission directly from the copyright holder. To view a copy of this license, visit http://creativecommons.org/licenses/by/4.0/.

(C) The Author(s) 2021 